\title{
Dendritic Cells in Experimental Renal Inflammation - Part I
}

\author{
Maja Lindenmeyer ${ }^{a} \quad$ Elfriede Noessner $^{c}$ Peter J. Nelson ${ }^{d}$ Stephan Segerer ${ }^{a}$ b \\ a Division of Nephrology, University Hospital Zurich, and ${ }^{\mathrm{b}}$ Institute of Anatomy, University of Zurich, Zurich, Switzerland; \\ 'Institute of Molecular Immunology, Helmholtz Zentrum München, German Research Center for Environmental Health, and \\ ${ }^{\mathrm{d}}$ Medizinische Poliklinik - Innenstadt, University of Munich, Munich, Germany
}

\section{Key Words}

Dendritic cells $\cdot$ Glomerulonephritis $\cdot$ Interstitial

inflammation $\cdot$ Experimental renal inflammation

\begin{abstract}
Dendritic cells (DCs) are bone marrow-derived professional antigen-presenting cells that act as master regulators of acquired and innate immune responses. While descriptions of cells with dendritic morphology in rodent kidneys date back to the early 1970s, a network of DCs in the mouse kidney has only recently been described. DCs acquire distinct phenotypic and functional characteristics depending on the microenvironment and the disease stages. Concomitantly, their communication with cells of the adaptive immunity might have tissue-protective or tissue-deleterious consequences. This review summarizes results from recent studies on the role of DCs in experimental renal inflammation.
\end{abstract}

Copyright $\odot 2011$ S. Karger AG, Basel

\section{Introduction}

Dendritic cells (DCs) were first identified in the mouse as a discrete cell type in lymphoid organs (spleen) that were characterized by a large stellate morphology [1]. These cells were subsequently found to be responsible for activation of the so-called mixed lymphocyte reaction used to characterize the major histocompatibility locus $[2,3]$. DCs are now recognized as the most potent class of antigen-presenting cells that play central roles in the initiation and control of the adaptive immune response [4, 5]. These cells ultimately help regulate the immune decisions that moderate the balance between tolerance and immunity $[6,7]$.

DCs are highly migratory cells that move from tissue to lymph nodes via afferent lymphatics where they then encounter naïve T cells (fig. 1). At steady state, they reside in the peripheral organs as immature cells with a high phagocytic activity. This allows them to constantly sample antigens from the extracellular space. Proteolytic enzymes within the cell digest the captured antigens into fragments (peptides), which are then presented at the DC cell surface via major histocompatibility complex (MHC) class I and class II proteins. In the absence of inflammation, DCs have high phagocytic activity, low T cell stimulatory capacity, and are involved in the regulation of immune tolerance. Upon exposure to microbial products or inflammatory stimuli, DCs undergo functional maturation and licensing to become potent activators of $\mathrm{T}$ cell immunity. The induction of high levels of costimulatory molecules and the secretion of T cell-activating cytokines (IL-12) are factors that define the T cell stimulatory capacity of DCs.

\section{KARGER \\ Fax +4161306 1234 E-Mail karger@karger.ch} www.karger.com

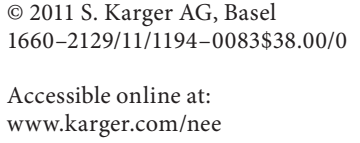

Stephan Segerer, MD

Division of Nephrology, University Hospital Zurich

Rämistrasse 100

CH-8091 Zurich (Switzerland)

Tel. +41 4425596 98, E-Mail stephan.segerer@usz.ch 


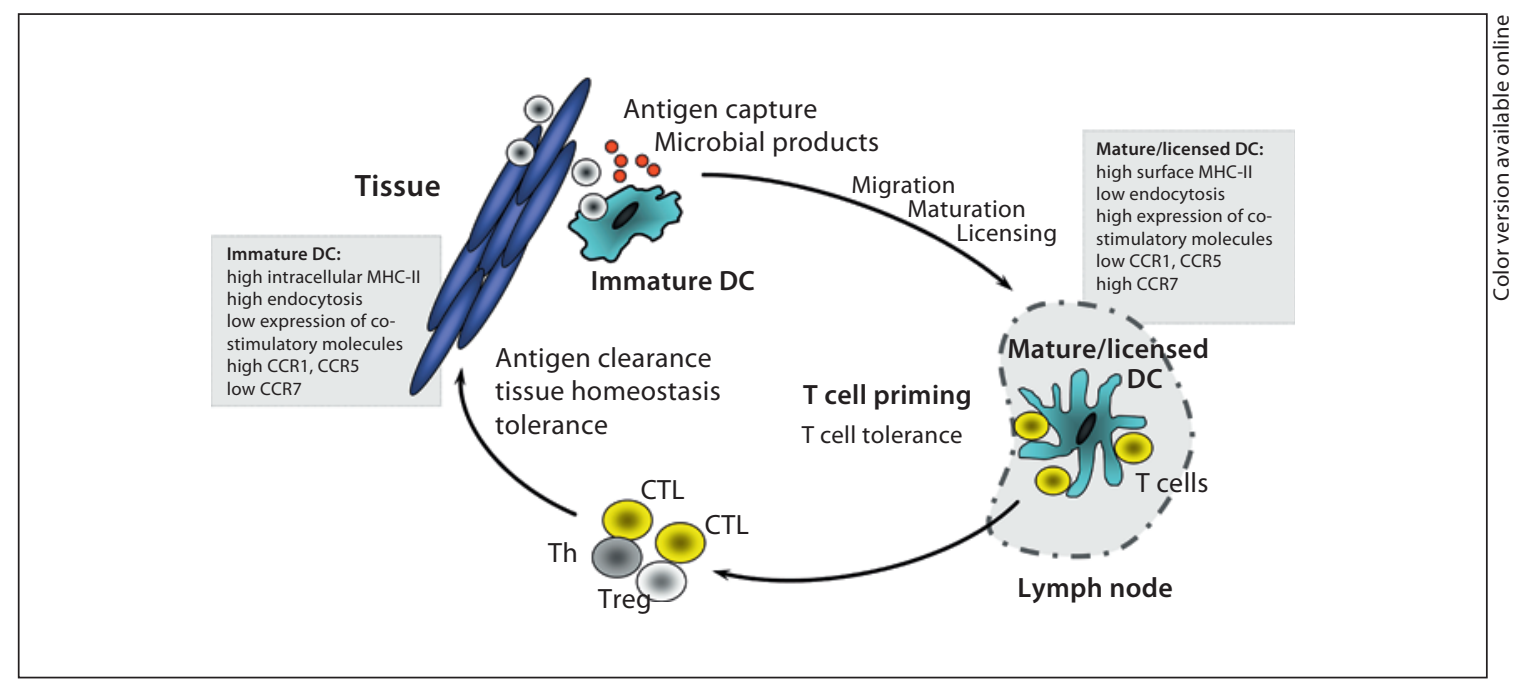

Fig. 1. Life cycle of a DC. DCs reside in peripheral tissues as immature DCs with high intracellular MHC class II and low costimulatory molecules. Due to their high endocytosis and phagocytosis, they continuously sample the extracellular environment. Engulfed proteins reach the lymph node via immature/non-licensed DCs showing constitutive low migratory activity. Due to low levels of costimulatory molecules and other not yet precisely defined mechanisms, these non-licensed DCs are thought to help regulate tolerance to peripheral tissue antigens. The presence of 'danger signals', e.g. microbial products, induces DC maturation and licensing which enhances their migratory activity to the lymph node due to upregulation of lymph node directing chemokine receptor CCR7. Microbial products also cause upregulation of costimulatory molecules and surface MHC class II, contributing to DC licensing which enables DCs to prime T cells in the lymph node. Activated T effector cells (cytotoxic T lymphocytes, CTL, or helper T cells, Th) or Treg, induced in situations where DCs are not licensed by 'danger signals', will return to the tissue to clear antigen and help establish tissue homeostasis or tolerance to tissue antigens.

The relevant processes underlying the tolerogenic state are incompletely understood, but are thought to involve active 'suppressive' signaling by endogenous agonists rather then just an absence of 'activating signals' [8]. This review focuses on experimental studies in rodents on the role of DCs in renal inflammation. A general review on the biology of DCs in human renal inflammation is discussed by Noessner et al. [9] in this issue of Nephron Experimental Nephrology.

\section{Mouse DC Subsets}

Since their initial description, many different subsets of DCs have been identified based on expression patterns of marker proteins (table 1; fig. 2). Many excellent indepth reviews have recently addressed the issue of DC diversity and highlight the current difficulty in precisely defining DC subsets, as well as their distinction from monocytes and tissue macrophages [10-14]. The phenotypic and functional plasticity has emerged as a hallmark of the DC/macrophage lineage. It now appears that the macrophage/DC distinction may be more accurately seen as a continuum of different cell stages. The surface marker CD11c and high expression of MHC class II still represent reliable markers for the identification of DCs in mice and allow their discrimination from macrophages (which express CD11b and are MHC class II low). By contrast, CD11c is inappropriate for DC identification in humans as it is broadly expressed by nearly all monocytes and macrophages. In mouse, CD11c is additionally found on alveolar macrophages $[15,16]$.

With the exception of follicular DCs (FDCs), DCs belong to the hematopoietic cell lineage. These cells are defined by the absence of lineage markers, combined with the expression of MHC class II, as well as a variety of adhesion molecules and costimulatory molecules depending on their maturation and activation status. There are several types of DCs which are characterized by different markers and functions (table 1; fig. 2). Based on precursor-product relationships, there is general agreement how to distinguish Langerhans cells (LCs) from plasmacytoid 
Fig. 2. Mouse DC development and DC subsets. A rough overview of DC development and subset specification. DCs derive from hematopoietic precursors (HSC) and develop along two branches: the lymphoid branch gives rise to the $\mathrm{pDCs}$ and the myeloid branch gives rise to the tissue LCs (CD207/Langerin+) as well as the bloodresident monocytes and cDCs. During the recruitment to peripheral tissues, DCs further diversify and may express a variety of markers. The cDCs can be further divided into the so-called type $1 \mathrm{cDCs}$ (CD8-) and type 2 cDCs (CD8+). For corresponding functions, see table 1 .

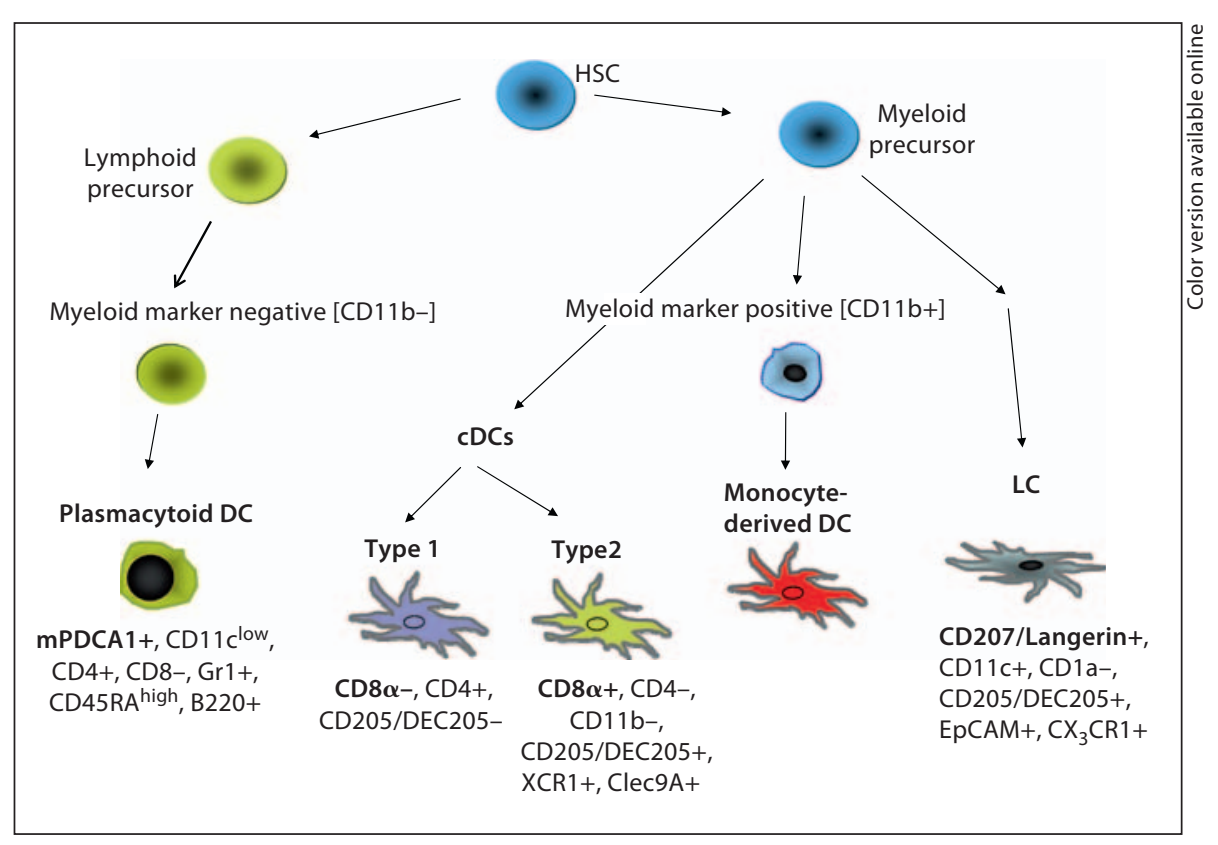

Table 1. DC subsets, phenotypic markers, and functional characteristics (mouse)

\begin{tabular}{|c|c|c|}
\hline DC subset & Phenotypic markers & Proposed function \\
\hline $\mathrm{LC}$ & $\begin{array}{l}\text { myeloid marker positive }[\mathrm{CD} 11 \mathrm{~b}+] \\
\text { CD207/Langerin }+, \mathrm{CD} 11 \mathrm{c}+, \mathrm{CD} 1 \mathrm{a}-, \mathrm{CD} 205+, \text { EpCAM+, } \mathrm{CX}_{3} \mathrm{CR} 1+\end{array}$ & $\begin{array}{l}\text { first immunologic barrier to the external } \\
\text { environment }\end{array}$ \\
\hline $\mathrm{pDC}$ & $\begin{array}{l}\text { myeloid marker negative [CD11b-] } \\
\text { mPDCA1+, CD11 }{ }^{\text {low }}, \text { CD } 4+, \text { CD8-, Gr1+, CD } 45 \mathrm{RA}^{\text {high }} \\
\text { B220+ (B cell marker) }\end{array}$ & $\begin{array}{l}\text { high production of type I interferons } \\
(\text { IFN } \alpha / \beta) \text {, antiviral response }\end{array}$ \\
\hline Myeloid DC & CD11chigh, CD45RA- & \\
\hline cDC type 1 & CD8-, CD4+, CD11b+, DEC205- (CX 3 CR1), (F4/80), (CD103) & CD4 T cell priming \\
\hline cDC type 2 & CD8+, CD4-, CD11b-, CD205/DEC205+, XCR1+, Clec9A+ & $\begin{array}{l}\text { cross-presentation } \rightarrow \text { CD8 T cell response } \\
\text { TGF- } \beta \rightarrow \text { tolerance }\end{array}$ \\
\hline \multicolumn{2}{|c|}{ Monocyte-derived DC ( $\left.\mathrm{CX}_{3} \mathrm{CR} 1\right),(\mathrm{F} 4 / 80),(\mathrm{CD} 103)$} & inflammation, tissue repair, homeostasis \\
\hline
\end{tabular}

(pDCs) and myeloid DCs. Myeloid DCs can be further subdivided into conventional (monocyte-independent) DCs (cDCs) and monocyte-derived DCs.

LCs were first recognized as different from splenic DCs based on the presence of Birbeck granules, which are Langerin positive. LCs reside in the epidermis and other

Dendritic Cells in Experimental Renal Inflammation stratified squamous epithelia. They are thought to have self-renewal capacity and thus act as their own cellular precursor.

The pDCs were initially isolated from tonsil, and were referred to as natural type I interferon-producing cells based on their high cytokine production in response to

Nephron Exp Nephrol 2011;119:e83-e90 e85 
viruses [17-20]. In mice, pDCs express the $B$ cell marker B220. They are CD11c low CD11b-CD45RA ${ }^{\text {high }}$ [21] and express murine plasmacytoid DC antigen 1, also known as bone marrow stromal cell antigen 2 [22].

Murine myeloid DCs are further subdivided by expression of $\mathrm{CD} 8 \alpha$. The $\mathrm{CD} 8 \alpha-\mathrm{CD} 11 \mathrm{c}+\mathrm{CD} 11 \mathrm{~b}+$ CD45RA- cells represent the most frequent myeloid DC subset, and are mainly involved in the priming of CD4 T cells. While less prevalent, the CD8 $\alpha+$ DC subset is the principal producer of IL-12, and thereby drives Th1 development and promotes CD8 $\mathrm{T}$ cell responses [12]. The most outstanding feature of the CD8 $\alpha+\mathrm{DC}$ subset is its high capacity to cross-present antigen which is necessary to exert two opposing functions. On the one hand, it allows priming of CTL against viruses that do not directly infect DCs, while on the other hand it induces CD8 T cell tolerance against self-antigens that are only expressed in certain tissues and not by the DCs themselves [23] Reflecting these functions, CD8 $\alpha+$ DCs also express Clec9A, a receptor for necrotic cells, and they can produce TGF- $\beta$ which can promote the generation of inducible $\mathrm{T}$ regulatory cells [24].

FDCs are a specialized subset of DCs which are not derived from the hematopoietic lineage [25]. These cells are found in the B cell zone of secondary lymphoid tissues and can retain antigen for longer periods of time. FDCs can restimulate both $\mathrm{B}$ cells and $\mathrm{T}$ cells, and appear to help maintain immune memory in tandem with B cells. They do not express common myeloid or lymphoid markers.

\section{DCs in Non-Lymphoid Peripheral Tissues}

The biology of DCs in non-lymphoid peripheral tissues is a developing field that is revealing an increase in the complexity of DC subsets - as phenotypic and functional adaptations occur in response to local tissue-specific microenvironments. The best-defined subset is the LC found in the skin. Other peripheral organs that have been studied in some detail with regard to their DC biology include the gut, the lung [reviewed in 26] and more recently the kidney [27-29]. Monocytes infiltrate tissue and can become phenotypically and functionally polarized by specific tissue microenvironments giving rise to various non-lymphoid tissue DC subpopulations [30]. The chemokine receptor $\mathrm{CX}_{3} \mathrm{CR} 1$ and the integrin $\alpha \mathrm{E} \beta_{7}$ (CD103) reciprocally define phenotypically, and functionally, distinct myeloid DC subsets. The CX3CR1+ cells migrate poorly, and are thought to participate in the local activation of effector or memory $\mathrm{T}$ cells that infiltrate the tissue. The CD103+ DCs represent a smaller percentage of the tissue DC population and have been proposed to be related to the lymphoid CD $8 \alpha+$ DCs. They are migratory and have the capacity to cross-present antigen, and thus may be responsible for generating CTL immunity and tolerance to tissue-associated pathogens and antigens, respectively $[23,24,31]$.

\section{DCs in Animal Models of Renal Inflammation}

Tubulointerstitial cells that showed a dendritic morphology, expressed MHC class II molecules, were first identified in the kidney almost 20 years ago $[32,33]$. The lack of reliable DC specific markers and general difficulties in isolating these cells has delayed the further characterization of renal DCs as a unique cell type. Kruger et al. [34] made important early contributions to the field of renal DC biology. In 2004, they described a subpopulation of tubulointerstitial cells expressing the murine DC marker CD11c+ in healthy murine kidneys. Further analysis of the CD11c+ cells showed that they were a non-homogenous cell population as shown by coexpression patterns for MHC class II, F4/80 and CD11b (macrophage markers) [34]. The cells were found to express various costimulatory molecules indicating different maturation and activation stages [34]. Functional analysis of the renal CD11c+ cell population further classified these as DCs, as demonstrated by their ability to activate naive T cells [34].

The potential role of renal DCs in the onset and progression of kidney diseases has been subject of many studies in the mouse kidney, which have been recently reviewed in detail [35-38]. While the current data illustrate various roles of DCs in the disease process, our understanding of DCs in renal diseases is still incomplete. Some studies have illustrated protective effects of renal DCs, other studies support a proinflammatory activity in renal disease settings.

\section{DCs in Nephrotoxic Glomerulonephritis}

In the most commonly used glomerular injury model (i.e. nephrotoxic nephritis, NTN), an accumulation of $\mathrm{CD} 11 \mathrm{c}+$ cells within the tubulointerstitial compartment, and accentuated in the periglomerular space around inflamed glomeruli was observed, while no positive cells were found within the inflamed glomerular tufts [34]. CD11c+ cells isolated from nephritic kidneys demon- 
strated an increased potential for $\mathrm{T}$ cell activation as compared to those from healthy mice $[34,39]$. To analyze the functional relevance of these infiltrating cells in NTN, Scholz et al. [39] depleted CD11c+ cells in nephritic CD11c-DTR-mice after 4 and 10 days of NTN induction. This led to an aggravation of the disease. Unexpectedly, an increased severity of tubulointerstitial and glomerular damage, proteinuria and decreased creatinine clearance were described in animals depleted of DCs. In addition, they demonstrated that renal DCs from nephritic mice not only induced the production of the Th1 cytokine IFN- $\gamma$, but also fostered an increase in secretion of the anti-inflammatory cytokine IL-10 by CD4+ Th1 cells [39] - previously been shown to attenuate crescentic GN [40]. These data suggest a renoprotective role of renal DCs in early NTN, probably through induction of IL-10. Recently, a functional switch of renal DCs in NTN - depending on the disease stage - has been described [41]. $\mathrm{CD} 11 \mathrm{c}+$ cells acquired a proinflammatory functionality during the course of the disease as shown by their increased expression of costimulatory molecules such as CD80 or CD86, and secretion of proinflammatory cytokines including TNF- $\alpha$ and interleukin-12. At the same time, the production of the suppressive molecule ICOS-L was found to be decreased. By contrast, the acquired proinflammatory activity led to an increased activation of $\mathrm{T}$ cells in the later stages of NTN as defined by enhanced production of proinflammatory cytokines IFN- $\gamma$, TNF$\alpha$, IL-17, IL-2, and IL-6 [41]. In the nephritic mice, proteinuria resulted in increased capture of antigen by interstitial DCs as compared to healthy mice, indicating a potential harmful role of proteinuria by stimulating nephritogenic immune responses [41]. In contrast to the observations at the early stage of NTN, the authors found an attenuation of the disease after depleting CD11c+ cells at a late stage of NTN, suggesting a switch of renal DCs from a protective to an aggravating functionality [41].

\section{DCs in T Cell-Mediated Glomerulonephritis}

In a model of $\mathrm{T}$ cell-mediated glomerular injury, additional roles of renal DCs were described by Heymann et al. [42]. They generated transgenic mice selectively expressing foreign model autoantigens (ovalbumin, OVA, or hen egg lysozyme) in podocytes. This was followed by an adoptive transfer of T cells specifically recognizing the antigens (OT-I cells: OVA-specific CD8+ CTLs; OT-II cells: OVA-specific CD4+ Th cells). The authors showed that injection of a single $\mathrm{T}$ cell type did not result in renal damage, while coinjection of CD8+ CTLs and preactivated CD4+ T cells into the transgenic mouse strain induced periglomerular accumulation of T cells, DCs, and macrophages [42]. Repeated injection of OT-I and OT-II cells for 4 weeks led to pronounced tubulointerstitial infiltration by mononuclear cells and the development of GN. In this experimental setting, renal DCs played an important role in the control of $\mathrm{T}$ cell infiltration and maintenance of the periglomerular infiltrate as depletion of CD11c+ cells resulted in rapid disappearance of infiltrating cells and attenuation of the disease [42]. Interstitial renal DCs cross-presented glomerular autoantigen and activated CD8+ CTLs (in renal lymph nodes), which in turn were activated to proliferate and eventually infiltrate the kidney leading to further OVA release. The proinflammatory activity of renal DCs was amplified by presentation of the glomerular autoantigen to CD4+ T cells in the kidney, and resulted in cytokine and chemokine secretion, further amplifying mononuclear infiltration of the periglomerular space [42]. Based on these results, kidney DCs appear to serve as a potential link between glomerular injury and disease progression to the tubulointerstitium.

\section{DCs in Experimental Lupus Nephritis}

Glomerulonephritis is one of the most common manifestations of systemic lupus erythematosus that affects $30-60 \%$ of the patients. It is initiated by glomerular deposition of immune complexes followed by an imbalance of cytokine homeostasis resulting in renal inflammation. Several animal models mimicking human lupus have been established, such as MRL/lpr or NZB/W F1 mice which carry allelic variants or mutations in specific genes leading to dysregulation of the cellular and humoral immunity [43-45]. Studies analyzing the contribution of resident renal DCs to the pathogenesis of lupus nephritis indicate a proinflammatory role of this cell subset [4547]. Iwata et al. [46] have recently shown that treating MRL/lpr mice with a p38 MAPK inhibitor reduced the infiltration of immature and mature CD11c+ DCs into the kidney and spleen and attenuated renal pathological changes including proliferative glomerulonephritis and interstitial/perivascular damage. In addition, they observed that $\mathrm{p} 38$ inhibition led to a decrease in production of the proinflammatory mediator high mobility group box (HMGB-1) protein in vivo and to inhibition of DC maturation and HMGB-1 excretion in vitro [46]. 
Castellano et al. [47] investigated the contribution of renal DCs and complement production in a murine model of progressive lupus nephritis. The authors found local and time-dependent synthesis of Clq, a component of the classical complement pathway, in kidneys of MRL/lpr mice. Confocal microscopy analysis identified renal CD11c+ DCs as the source of the C1q [47]. These results suggest that DCs participate in the 'autoimmunity' of lupus nephritis via secretion of proinflammatory proteins, activation of the complement system and thus promote renal inflammation and progression of the disease.

\section{DCs in Ischemic Acute Kidney Injury}

The various animal models discussed above addressed events in the glomerular compartment; the following part will focus more on models of interstitial injury. In a model of acute renal ischemia/reperfusion injury (IRI), Dong et al. [48] identified resident renal DCs as the major source of the inflammatory mediator TNF$\alpha$. Flow cytometry analysis of bone marrow-derived (CD45+) cells indicated a proportional increase in all CD $45+$ cell populations (monocytes, neutrophils, T cells and F4/80 - DCs) in ischemic kidneys, with the exception of F4/80+ DCs, which remained unchanged [48]. The $\mathrm{CD} 11 \mathrm{c}+\mathrm{F} 4 / 80+\mathrm{CD} 11 \mathrm{~b}+\mathrm{DCs}$ were shown to be the predominant cell type among the TNF-expressing cells. Treatment with clodronate before onset of IRI, which depletes macrophages and DCs, resulted in a marked reduction of TNF secretion by total and CD 45+ renal cells, confirming resident renal DCs as major producers of TNF in early IRI [48].

A recent study by Lech et al. [49] proposed a protective role of renal DCs in postischemic acute renal failure. The authors demonstrated that the single Ig IL-1-related receptor (SIGGIR) suppresses immune cell activation in postischemic acute renal failure as SIGGIR-deficient mice displayed an aggravation of the disease [49]. IRI in SIGGIR-deficient mice showed an enhancement of interstitial leukocyte recruitment, transendothelial migration, and increased Il-6, CCl2, and $\mathrm{CXCl} 2$ mRNA expression in CD11b+ cells, but not in tubular epithelial cells. Depletion of DCs with clodronate prevented aggravation of IRI in the SIGGIR-deficient mice suggesting a suppressive role of renal SIGGIR-expressing DCs in IRI [49].

Kim et al. [50] investigated the role of renal DCs in the recovery phase of IRI. The authors showed that in- travenous clodronate treatment after IRI resulted in a preferential depletion of renal CD11c+ F4/80+ DCs on day 7. While previous studies had demonstrated that clodronate depletion before IRI resulted in a marked decrease in kidney damage, Kim et al. [50] observed that depletion of renal DCs after IRI led to an impaired kidney recovery as it was associated with (a) increased apoptosis, (b) impairment of tubular cell proliferation, and (c) increased inflammatory milieu as shown by higher number of neutrophils in the kidney, and higher expression levels of proinflammatory cytokines and reduced levels of IL-10. Renal CD11c+ DCs isolated in the recovery phase of IRI (day 7) displayed a rather antiinflammatory expression profile (lower levels of proinflammatory TNF- $\alpha$, IL- 6 and IFN- $\gamma$, with increased production of the anti-inflammatory IL-10), as compared to renal DCs isolated at the early perfusion phase (day one). These results, as well as the fact that the adoptive transfer of DCs to clodronate-treated mice could partially reverse renal injury, indicate a beneficial role of renal DCs in the recovery phase of IRI by changing from a pro- to an anti-inflammatory phenotype and modulation of the immune response [50].

\section{DCs in Cisplatin-Mediated Acute Kidney Injury}

Cisplatin is a widely used anticancer drug, with adverse side effects on acute renal function caused by tubular injury. Recent studies by Tadagavadi and Reeves [51, 52] investigated the contribution of renal DCs in a model of cisplatin nephrotoxicity. They used CD11c-DTRtg mice in which DCs expressed the green fluorescent protein and the diphtheria toxin receptor [51]. Ablation of CD11c+ DCs before cisplatin treatment resulted in an aggravated renal injury as shown by an increased tubular injury, increased neutrophil infiltration and reduced survival rates [51]. By using mixed bone marrow chimeras in which $50 \%$ of the DCs were WT- and the other $50 \%$ CD11c-DTRtg-derived DCs, the authors could exclude inflammatory effects of dead or dying DCs in the DCablated mice on the worsening of the nephrotoxicity. DT treatment of these chimeric mice had no effect on the severity of renal dysfunction [51]. Treatment of mice with cisplatin increased the production of ICOS-L by renal DCs, a known inducer of IL-10. These results suggest that renal DCs can attenuate toxin-induced acute kidney injury by modulating the inflammatory response. In a second study, the authors used the same model system to determine the role of endogenous and DC-released anti- 
inflammatory IL-10 [52]. Treating mice with cisplatin resulted in activation of IL-10 receptor (IL-10R) signaling as shown by increased serum IL-10 levels, renal IL-10R1 expression, and renal STAT3 phosphorylation. IL-10-deficient mice displayed a worse outcome in cisplatin nephropathy with decreased renal function, higher expression levels of inflammatory chemokines, and an increased infiltration of IFN- $\gamma$-producing neutrophils [52]. To further characterize the source of IL-10, the authors used mixed bone-marrow chimeric mice where leukocytes were derived from CD11c-DTRtg and IL-10 KO mice. Mixed bone marrow chimeric mice lacking IL-10 production by DCs displayed a greater decrease in renal function than mice with IL-10-producing DCs. This is consistent with a protective effect of DCs mediated by DC-derived IL-10 in the context of cisplatin nephrotoxicity [52].

\section{Conclusion}

Taken together, these studies suggest various roles for renal DCs depending on the intrarenal inflammatory conditions and the maturation state of the resident DCs. However, why renal DCs appear to switch between 'good cops' and 'bad cops' in renal inflammatory disorders, and what the contribution of DC maturation is to the progression of renal disease, remains to be seen.

\section{Acknowledgements}

S.S. is supported by a grant from the University of Zurich, a Clinical Evidence Council grant from Baxter Healthcare Corporation and from the Swiss National Science Foundation (32003B_129710). E.N. is supported by SFB-TR36 and P.J.N. by SFB-571 from the Deutsche Forschungsgemeinschaft.

\section{References}

1 Steinman RM, Cohn ZA: Identification of a novel cell type in peripheral lymphoid organs of mice. I. Morphology, quantitation, tissue distribution. J Exp Med 1973;137: 1142-1162.

-2 Steinman RM, Lustig DS, Cohn ZA: Identification of a novel cell type in peripheral lymphoid organs of mice. III. Functional properties in vivo. J Exp Med 1974;139:1431-1445.

-3 Steinman RM, Cohn ZA: Identification of a novel cell type in peripheral lymphoid organs of mice. II. Functional properties in vitro. J Exp Med 1974;139:380-397.

4 Banchereau J, Palucka AK: Dendritic cells as therapeutic vaccines against cancer. Nat Rev Immunol 2005;5:296-306.

5 Banchereau J, Steinman RM: Dendritic cells and the control of immunity. Nature 1998 392:245-252.

6 Mahnke K, Schmitt E, Bonifaz L, Enk AH, Jonuleit $\mathrm{H}$ : Immature, but not inactive: the tolerogenic function of immature dendritic cells. Immunol Cell Biol 2002;80:477-483.

$\checkmark 7$ Steinman RM, Hawiger D, Nussenzweig MC: Tolerogenic dendritic cells. Annu Rev Immunol 2003;21:685-711.

$\checkmark 8$ Mellman I, Clausen BE: Immunology. Betacatenin balances immunity. Science 2010; 329:767-769.

$\checkmark 9$ Noessner E, Lindenmeyer M, Nelson PJ, Segerer S: Dendritic cells in human renal inflammation. Nephron Exp Nephrol 2011;119:e91-e98.

-10 Geissmann F, Gordon S, Hume DA, Mowat AM, Randolph GJ: Unravelling mononuclear phagocyte heterogeneity. Nat Rev Immunol 2010;10:453-460.
11 Steinman RM, Idoyaga J: Features of the dendritic cell lineage. Immunol Rev 2010;234 5-17.

12 Naik SH: Demystifying the development of dendritic cell subtypes, a little. Immunol Cell Biol 2008;86:439-452.

13 Auffray C, Sieweke MH, Geissmann F: Blood monocytes: development, heterogeneity, and relationship with dendritic cells. Annu Rev Immunol 2009;27:669-692.

14 Heath WR, Carbone FR: Dendritic cell subsets in primary and secondary $\mathrm{T}$ cell re sponses at body surfaces. Nat Immunol 2009; 10:1237-1244.

15 Ferenbach D, Hughes J: Macrophages and dendritic cells: what is the difference? Kidney Int 2008;74:5-7.

16 van Rijt LS, Jung S, Kleinjan A, Vos N, Willart M, Duez C, Hoogsteden HC, Lambrecht $\mathrm{BN}$ : In vivo depletion of lung CD11c+ dendritic cells during allergen challenge abrogates the characteristic features of asthma. J Exp Med 2005;201:981-991.

17 Perussia B, Fanning V, Trinchieri G: A leukocyte subset bearing HLA-DR antigens is responsible for in vitro alpha interferon production in response to viruses. Nat Immun Cell Growth Regul 1985;4:120-137.

-18 Fitzgerald-Bocarsly P, Feldman M, Mendelsohn M, Curl S, Lopez C: Human mononuclear cells which produce interferon-alpha during NK(HSV-FS) assays are HLA-DR positive cells distinct from cytolytic natural killer effectors. J Leukoc Biol 1988;43:323334.
19 Siegal FP, Kadowaki N, Shodell M, Fitzgerald-Bocarsly PA, Shah K, Ho S, Antonenko S, Liu YJ: The nature of the principal type 1 interferon-producing cells in human blood. Science 1999;284:1835-1837.

20 Cella M, Jarrossay D, Facchetti F, Alebardi O, Nakajima H, Lanzavecchia A, Colonna M: Plasmacytoid monocytes migrate to inflamed lymph nodes and produce large amounts of type I interferon. Nat Med 1999; 5:919-923.

21 O'Keeffe M, Hochrein H, Vremec D, Scott B, Hertzog P, Tatarczuch L, Shortman K: Dendritic cell precursor populations of mouse blood: identification of the murine homologues of human blood plasmacytoid preDC2 and CD11c+ DC1 precursors. Blood 2003;101:1453-1459.

22 Blasius AL, Giurisato E, Cella M, Schreiber RD, Shaw AS, Colonna M: Bone marrow stromal cell antigen 2 is a specific marker of type I IFN-producing cells in the naive mouse, but a promiscuous cell surface antigen following IFN stimulation. J Immunol 2006;177:3260-3265.

23 Bedoui S, Whitney PG, Waithman J, Eidsmo L, Wakim L, Caminschi I, Allan RS, Wojtasiak M, Shortman K, Carbone FR, Brooks AG, Heath WR: Cross-presentation of viral and self antigens by skin-derived CD103+ dendritic cells. Nat Immunol 2009;10:488495.

24 del Rio ML, Bernhardt G, Rodriguez-Barbosa JI, Forster R: Development and functional specialization of CD103+ dendritic cells. Immunol Rev 2010;234:268-281. 
25 Allen CD, Cyster JG: Follicular dendritic cell networks of primary follicles and germinal centers: phenotype and function. Semin Immunol 2008:20:14-25.

-26 Helft J, Ginhoux F, Bogunovic M, Merad M: Origin and functional heterogeneity of nonlymphoid tissue dendritic cells in mice. Immunol Rev 2010;234:55-75.

-27 Soos TJ, Sims TN, Barisoni L, Lin K, Littman DR, Dustin ML, Nelson PJ: CX3CR1+ interstitial dendritic cells form a contiguous network throughout the entire kidney. Kidney Int 2006;70:591-596.

28 Kim Z, Nelson PJ: Interfacing kidney stroma with dendritic cells. J Am Soc Nephrol 2009; 20:685-686.

-29 Nelson PJ: Renal ischemia-reperfusion injury: renal dendritic cells loudly sound the alarm. Kidney Int 2007;71:604-605.

- 30 Varol C, Landsman L, Fogg DK, Greenshtein L, Gildor B, Margalit R, Kalchenko V, Geissmann F, Jung S: Monocytes give rise to mucosal, but not splenic, conventional dendritic cells. J Exp Med 2007;204:171-180.

- 31 Edelson BT, Kc W, Juang R, Kohyama M, Benoit LA, Klekotka PA, Moon C, Albring JC, Ise W, Michael DG, Bhattacharya D, Stappenbeck TS, Holtzman MJ, Sung SS, Murphy TL, Hildner K, Murphy KM: Peripheral CD103+ dendritic cells form a unified subset developmentally related to CD8alpha+ conventional dendritic cells. J Exp Med 2010;207:823-836.

- 32 Kaissling B, Le Hir M: Characterization and distribution of interstitial cell types in the renal cortex of rats. Kidney Int 1994;45:709720.

-33 Austyn JM, Hankins DF, Larsen CP, Morris PJ, Rao AS, Roake JA: Isolation and charac terization of dendritic cells from mouse heart and kidney. J Immunol 1994; 152:24012410.

-34 Kruger T, Benke D, Eitner F, Lang A, Wirtz M, Hamilton-Williams EE, Engel D, Giese B, Muller-Newen G, Floege J, Kurts C: Identification and functional characterization of dendritic cells in the healthy murine kidney and in experimental glomerulonephritis. J Am Soc Nephrol 2004;15:613-621.
\$3 Rogers NM, Matthews TJ, Kausman JY, Kitching AR, Coates PT: Review article: kidney dendritic cells: their role in homeostasis, inflammation and transplantation. $\mathrm{Ne}$ phrology (Carlton) 2009;14:625-635.

36 Matsumoto K, Fukuda N, Abe M, Fujita T: Dendritic cells and macrophages in kidney disease. Clin Exp Nephrol 2010;14:1-11.

37 Hochheiser K, Tittel A, Kurts C: Kidney dendritic cells in acute and chronic renal disease. Int J Exp Pathol 2011;92:193-201.

38 Sung SS, Bolton WK: T cells and dendritic cells in glomerular disease: the new glomerulotubular feedback loop. Kidney Int 2010; 77:393-399.

39 Scholz J, Lukacs-Kornek V, Engel DR, Specht S, Kiss E, Eitner F, Floege J, Groene HJ, Kurts C: Renal dendritic cells stimulate IL-10 production and attenuate nephrotoxic nephritis. J Am Soc Nephrol 2008;19:527-537.

40 Kitching AR, Katerelos M, Mudge SJ, Tipping PG, Power DA, Holdsworth SR: Interleukin-10 inhibits experimental mesangial proliferative glomerulonephritis. Clin Exp Immunol 2002;128:36-43.

41 Hochheiser K, Engel DR, Hammerich L, Heymann F, Knolle PA, Panzer U, Kurts C: Kidney dendritic cells become pathogenic during crescentic glomerulonephritis with proteinuria. J Am Soc Nephrol 2011;22:306316.

42 Heymann F, Meyer-Schwesinger C, Hamilton-Williams EE, Hammerich L, Panzer U, Kaden S, Quaggin SE, Floege J, Grone HJ, Kurts C: Kidney dendritic cell activation is required for progression of renal disease in a mouse model of glomerular injury. J Clin Invest 2009;119:1286-1297.

43 Bagavant H, Fu SM: Pathogenesis of kidney disease in systemic lupus erythematosus. Curr Opin Rheumatol 2009;21:489-494.

44 Davidson A, Aranow C: Lupus nephritis: lessons from murine models. Nat Rev Rheumatol 2010;6:13-20.
45 Tucci M, Ciavarella S, Strippoli S, Dammacco F, Silvestris F: Oversecretion of cytokines and chemokines in lupus nephritis is regulated by intraparenchymal dendritic cells: a review. Ann N Y Acad Sci 2009;1173:449457.

46 Iwata Y, Furuichi K, Sakai N, Yamauchi H, Shinozaki Y, Zhou H, Kurokawa Y, Toyama T, Kitajima S, Okumura T, Yamada S, Maruyama I, Matsushima K, Kaneko S, Wada T: Dendritic cells contribute to autoimmune kidney injury in MRL-Faslpr mice. J Rheumatol 2009;36:306-314.

47 Castellano G, Trouw LA, Fiore N, Daha MR, Schena FP, van Kooten C: Infiltrating dendritic cells contribute to local synthesis of C1q in murine and human lupus nephritis. Mol Immunol 2010;47:2129-2137.

-48 Dong X, Swaminathan S, Bachman LA, Croatt AJ, Nath KA, Griffin MD: Resident dendritic cells are the predominant TNF-secreting cell in early renal ischemia-reperfusion injury. Kidney Int 2007;71:619-628.

49 Lech M, Avila-Ferrufino A, Allam R, Segerer S, Khandoga A, Krombach F, Garlanda C, Mantovani A, Anders HJ: Resident dendritic cells prevent postischemic acute renal failure by help of single Ig IL-1 receptor-related protein. J Immunol 2009; 183:4109-4118.

50 Kim MG, Boo CS, Ko YS, Lee HY, Cho WY, Kim HK, Jo SK: Depletion of kidney CD11c+ $\mathrm{F} 4 / 80+$ cells impairs the recovery process in ischaemia/reperfusion-induced acute kidney injury. Nephrol Dial Transplant 2010;25: 2908-2921.

-51 Tadagavadi RK, Reeves WB: Renal dendritic cells ameliorate nephrotoxic acute kidney injury. J Am Soc Nephrol 2010;21:53-63.

52 Tadagavadi RK, Reeves WB: Endogenous IL10 attenuates cisplatin nephrotoxicity: role of dendritic cells. J Immunol 2010;185:49044911.

53 Isaksson M, Ardesjo B, Ronnblom L, Kampe $\mathrm{O}$, Lassmann H, Eloranta ML, Lobell A: Plasmacytoid DC promote priming of autoimmune Th17 cells and EAE. Eur J Immunol 2009;39:2925-2935. 